\title{
Ventilated façade systems. Design and workmanship faults affecting the functionality and safe use
}

\author{
Oteksij Kopyłow ${ }^{1, *}$ \\ ${ }^{1}$ Building Research Institute, Building Elements Engineering Department, 02-656 Warsaw, \\ Ksawerów 21 street, Poland
}

\begin{abstract}
Ventilated facade systems are increasingly used in modern construction industry. It is connected with a wide range of available wall claddings which allow to create distinctive architectural buildings (ventilated facade system made of fiber cement sheets won the prestigious European Prize for Urban Public Space 2016). If constructed properly, the ventilated facade systems have a positive effect on thermal insulation properties of building walls. With an increasing interest in this type of facade solutions, one can also notice an increased number of problems with the quality of the design documentation and construction works which affect the safe use of the building, thermal insulation properties of partition walls, the comfort of use. The paper presents basic faults found in the design and workmanship of the ventilated facade systems.
\end{abstract}

\section{Introduction}

Recently investors and designers have increasingly used the ventilated facade systems in newly constructed and retrofitted buildings. The ventilated facade systems are the facade systems with air (ventilation) gap between the thermal insulation layer and the claddings where the air flows preventing moisture accumulation in this layer [1]. The principle of operation of the ventilated facade system is illustrated in Figure 1.

\footnotetext{
*Corresponding author: o.kopylov@itb.pl
} 


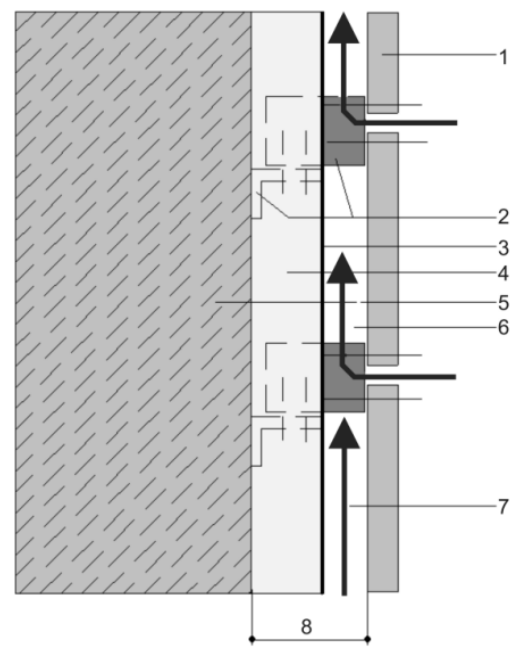

Fig. 1. Ventilated facade system diagram: 1 - façade cladding, 2 - framework, 3 - air barrier, 4 thermal insulation, 5 - external wall (Source [1]).

The ventilated facade systems become more and more popular because of their technical and performance as well as aesthetic properties. Properly designed and constructed ventilated facade systems (requirements for ventilated facade systems are specified in [1, 2]) are characterized by high durability, have a positive effect on thermal insulation properties of external walls. A wide range of available façade claddings, methods of fixing to the substructure [3] allows the architects to create a unique and modern facade system of the building, adjust it to any urban environment. Another reason for interest in the ventilated facade systems is of economic nature: modern ventilated facade systems are highly prefabricated which reduces the time and costs of assembly of the facade system. Large supply and competition on the market led to a considerable decrease in the prices of the ventilated facade systems. At present the systems of this type are selected not only for the walls of representative public buildings (banks, offices) but also for low budget investments: social residential buildings, nursery schools.

The increased number of ventilated facade systems is accompanied by an increase in failures of the solutions of this type due to design and workmanship faults. Major faults include the following: the use of ventilated facade systems without National Technical Assessments (hereinafter NTA) or European Technical Assessments (hereinafter ETA), noncompliance with the NTA/ETA provisions when designing facade systems, incorporating substitute materials and elements to the facade systems covered by NTA/ETA, constructing the facade system without a design or with a design that is not accurate enough. The faults mentioned have a significant impact on the safe use of the civil structures. Unfortunately many of them were the cause of death of people all around the world. The most spectacular was the fire of the high-rise building, Grenfell Tower in London in 2017. 


\section{Design faults}

The most common and severe fault at the stage of designing the ventilated facade system is the decision made on the use of products which are not accompanied by NTA/ETA as a standalone product. The above-mentioned documents include important information regarding the facade system design: maximum acceptable wind load values, the possibility to use in zones exposed to vandalism, thermal insulation parameters, issues connected with fire safety, the possibility to use in different corrosion environments, the possibility of resting ladders against the facade system, the possibility of using in climate zones with temperature below $0^{\circ} \mathrm{C}$.

Facade systems designed without using the data included in NTA/ETA may pose a threat to the life and health of users.

When designing the ventilated facade systems an important factor which increases the risk of failure is the failure to take account of some specific strength parameters of walls forming the base for the ventilated facade system and mechanical fixings used to attach the facade system to the wall: e.g. pull-out and shear resistance of mechanical fixings. The minimum bearing capacity parameters of walls shall be provided in the ventilated facade system design. For retrofitted buildings, before designing the ventilated facade system, it is necessary to have an expert opinion prepared and to carry out tests to determine the actual mechanical fixing pull-out and shear resistance of the wall and account for the abovementioned values in the design. For newly constructed buildings, before assembly of the ventilated facade system it is necessary to test the above-mentioned parameters in points selected at random ( 1 test per $50 \mathrm{~m}^{2}$ of the facade system) and compare the results with the design assumptions. If the facade system is attached to the walls characterized by the bearing capacity smaller than assumed, the facade system may come loose under its dead load or/and wind load.

The ventilated facade systems claddings may become damaged because of being attached to walls which deflect considerably from the straight line (by over $3 \mathrm{~mm} / 2 \mathrm{~m}$ ). The attachment of the framework elements to skewed walls may result in additional stresses on joints between individual framework elements and claddings and reduce strength and performance properties of the ventilated facade system. Therefore, to ensure safe use of the ventilated facade system, it is necessary to indicate limit acceptable wall curvatures in the design.

The safe use of the ventilated facade system is affected considerably by proper selection of the centre distance between the substructure elements. The National Technical Assessments/European Technical Assessments provide limit centre distance between framework elements subject to the wind load or the existing risk of impact. Larger centre distance are typical for facade system elements less exposed to wind load or the risk of impact. If the acceptable distances (indicated in ETA/NTA) between the framework elements are exceeded, it leads to reduction in resistance to wind load, impact and linear force acting horizontally.

The facade system claddings may become damaged if movement joins and substructure expansion joints are overlooked in the design. Movement and expansion joints cannot be overlooked because of large differences in the coefficient of thermal expansion of the claddings and the facade system framework.

When designing a ventilated facade system accompanied by the European Technical Assessment, it is necessary to pay special attention to technical and performance properties declared by the facade system manufacturer. Often the manufacturers of the ventilated facade systems from the southern Europe skip the climatic properties of the facade system, e.g. resistance to "heating-raining" or "heating-cooling" cycles. In the European Technical Assessments these properties are marked as not determined - NPD (No performance 
determined). If the ventilated facade system with the above-mentioned properties not determined is used in the Polish climatic conditions, it may pose a risk of failure of the facade system when exposed to lower temperature or sudden weather breakdown (rain on a hot day). The effect of climate cycles on the ventilated facade system is presented in Figure 1.

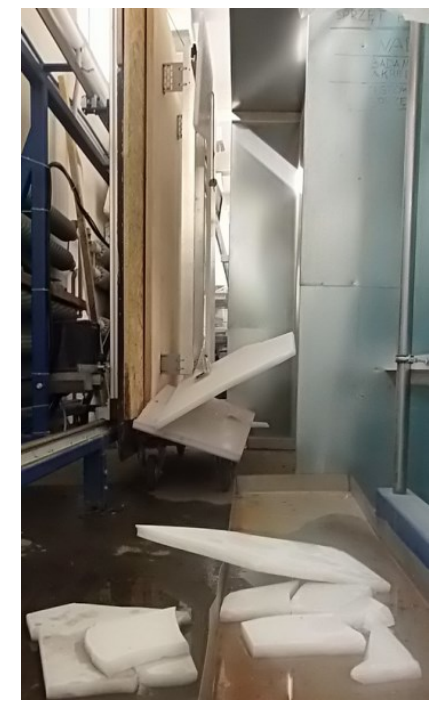

Fig. 1. The ventilated facade system damaged due to climate cycles.

Another technical property which may have an adverse effect on the safe use of the facade system placed on the market on the basis of ETA and which prevents its legal use in Poland is the missing proof of meeting the conditions referred to in paragraph 225 of Regulation of the Minister of Infrastructure on technical conditions to be met by buildings and their location [4]: "elements of façade claddings shall be fixed to the building in a manner preventing their falling out during a fire in a time shorter than resulting from the required fire resistance rating for an external wall, (...), correspondingly to the fire resistance rating of the building to which they are mounted".

Each façade system should be tested in the field of:

- reaction to fire;

- façade fire performance.

An untested façade system may be the cause of the tragedy. For example: the façade system used in the Grenfell Tower in London before installation was never tested in the field of fire safety. The façade of this building have been built as follows [5]:

- exterior cladding: aluminium sandwich plates $(3 \mathrm{~mm}$ each) with polyethylene core (the paper [6] shows that it was a combustible material);

- a standard ventilation gap $(50 \mathrm{~mm})$ between the cladding and the insulation behind it (the gap between the cladding and the insulation worked like a chimney to spread the fire);

- an insulation made of PIR (polyisocyanurate) foam plates $(150 \mathrm{~mm})$ mounted on the existing façade(this material burns when heated giving off toxic cyanide fumes).

Both the aluminium-polyethylene cladding and the PIR insulation plates failed fire safety tests conducted after the fire [7].

The use of spacers, which are not specified in NTA/ETA, under bracket footings to eliminate thermal bridges, may contribute to reduced fire safety of the ventilated facade system. These elements may considerably change the fire resistance of the facade system and its strength properties.

A very common fault in the design practices which affects the safe use of the building as a whole is the use of ventilated facade systems with claddings characterized by low resistance 
to impact in areas available to passers who care very little about the property. Such claddings may break or fall off under impact. Falling fragments may lead to serious bodily injuries suffered by users (Figure 2).

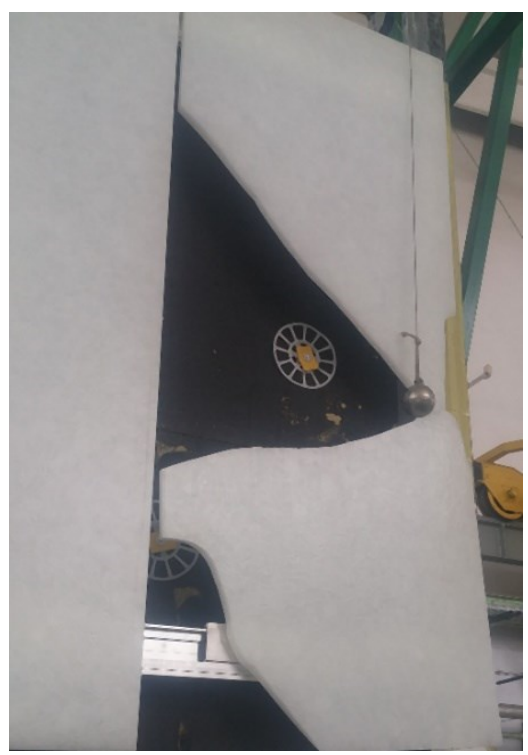

Fig. 2. Dangerous fragments of the ventilated facade system under hard body impact.

A common design fault is to use the ventilated facade system in the corrosive environment which is more aggressive than provided for in NTA/ETA. The corroded parts of the ventilated facade system may lead to its damage (Figure 3).

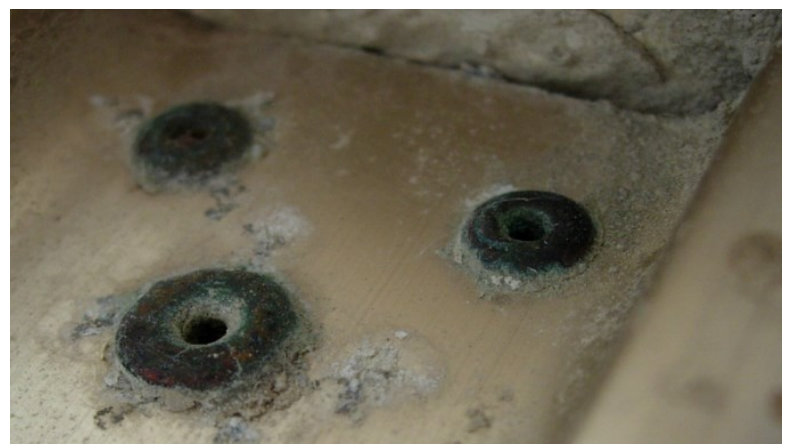

Fig. 3. Corroded rivets used to attach the ventilated facade system claddings to the framework.

When it comes to the maintenance of the required thermal insulation parameters of the space divider and the comfort of use, when designing the ventilated facade system it is necessary to account for air permeability of the walls to which the facade system shall be attached. A common fault is the designing of the ventilated facade system on walls made of masonry elements with unfilled perpends without additional blinding layers. It may be a direct cause of exceeded air exchange rate in the building and heat losses.

The thermal insulation properties of space dividers may be reduced by the use of the ventilated facade system with brackets without thermal spacers or other solutions preventing the occurrence of thermal bridges (Figure 4). The Regulation of the Minister of Infrastructure on technical conditions to be met by buildings and their location [4] provides that: "the values of the heat transfer coefficient UC of the walls (..) for all types of buildings, which account 
for adjustments made due to air gaps in the insulation layer, mechanical fixings penetrating the insulation layer (...), calculated according to the Polish Standards on calculation of heat resistance and heat transfer coefficient and heat transfer through soil, cannot be greater than UC (max)". Since 2017 it has been $0.23 \mathrm{~W} /\left(\mathrm{m}^{2} \mathrm{~K}\right)$.
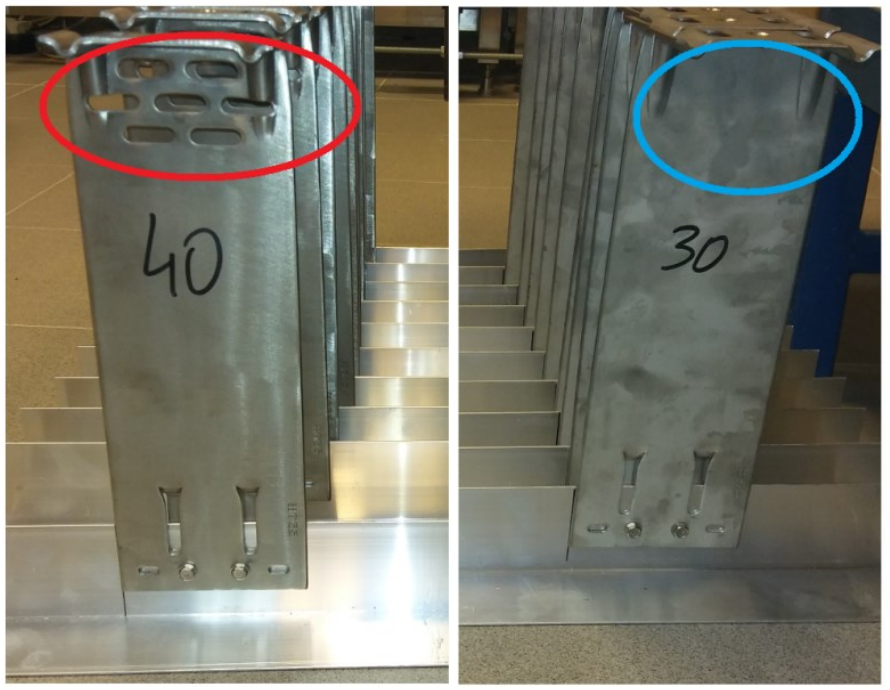

Fig. 4. Brackets for the ventilated facade system. The red circle is used to mark the solution which reduces the effect of thermal bridges.

\section{Workmanship faults}

One of basic workmanship faults with effect on safe use of the ventilated facade system is the overlooking of the substrate strength before commencement of the works. The pull-out and shear resistance of the substrate (wall) for the mechanical fixings used to attach the substructure shall not be smaller than that provided for in the design. Often, when attaching the ventilated facade systems to masonry walls the contractors set the mechanical fixings not in the masonry unit (as provided for in the design), but in the joint which considerably reduces the safe use of the facade system (Figure 5).

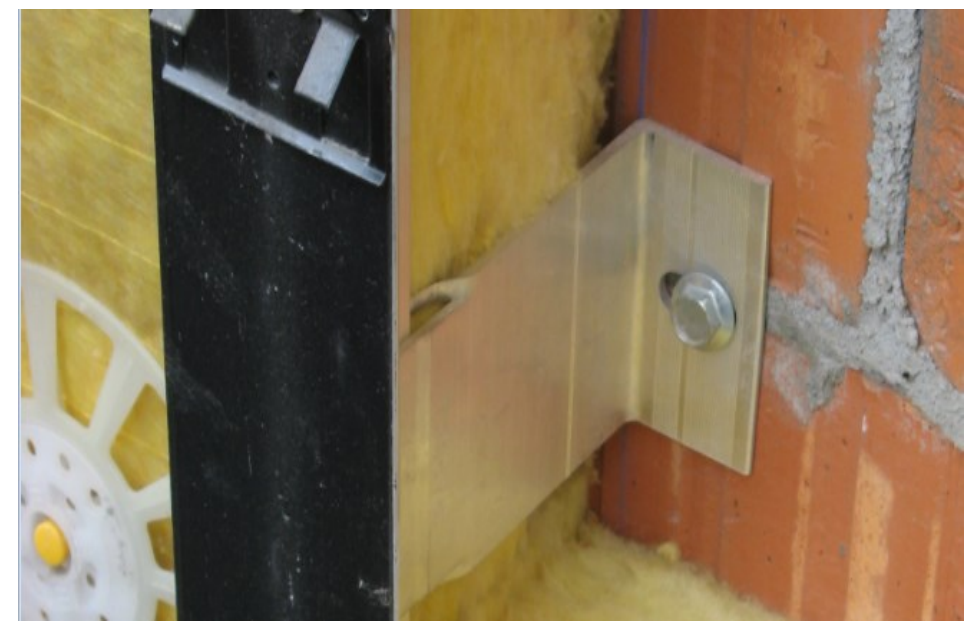

Fig. 5. The mechanical fixing of the ventilated facade system attached to the joint. 
The strength of the substrate (wall) on which the ventilated facade system shall be hung may be reduced by the use of inappropriate tools. For example, if the facade system is hung on a hollow tile wall, the use of a cushion drill may damage the bricks and prevent the use of mechanical fixings provided for in the design.

From the point of view of safe use of the ventilated facade system it is unacceptable to use the mechanical fixings other than provided for in NTA/ETA and the design. The use of fixings other than provided for in the design may affect the strength properties of the "fixingwall" connection, change the corrosion resistance of the facade system.

A very common workmanship fault is the attachment of the ventilated facade system to unprepared substrates: uneven, moist, with large cavities, with plaster falling off, etc. For walls with curvature of over $3 \mathrm{~mm} / 2 \mathrm{~mm}$ it is unacceptable to use spacers other than provided for in NTA/ETA to eliminate the wall curvature. The use of non-system elements may have a considerable effect on fire safety of walls and may reduce the bearing capacity of the brackets.

The strength properties of the ventilated facade system may be reduced by the use of substructure elements other than provided for in NTA/ETA. There are many instances of "leaning" the substructure, where the thickness of the bracket walls was changed to save the costs (Figure 6).

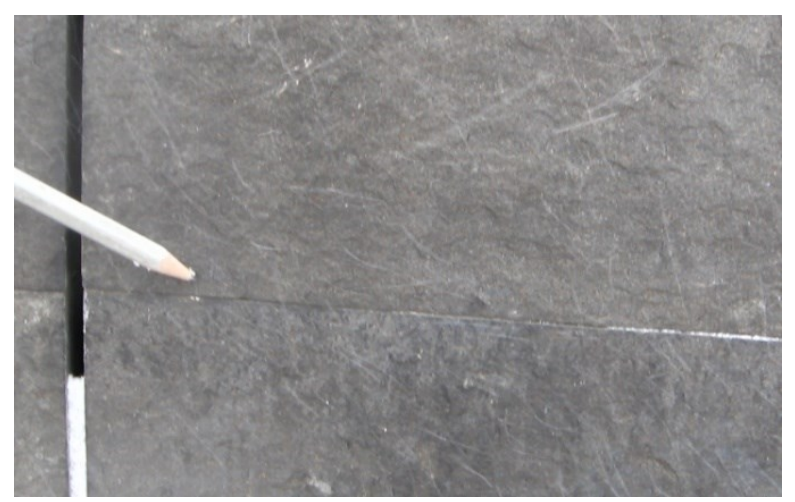

Fig. 6. Claddings of the ventilated facade systems subsiding as a result of reduced thickness of the walls of the substructure elements.

Often the facade system claddings are damaged because they become too stiff as a result of failure to use or improper execution of expansion joints which allow the cladding to deform slightly because of thermal expansion, wind load actions.

For claddings which are attached to the substructure with the use of adhesive, it is extremely important to use proper adhesive application method. Quite often the failure to comply with technical conditions for adhesive application is the cause of failure of the ventilated facade systems (Figure 7). Both the moisture content and air temperature at which the adhesive is applied have a very significant impact on the strength of the adhesive bond. 


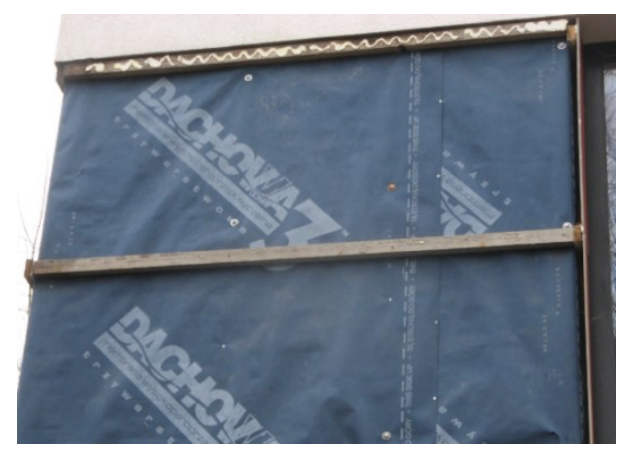

Fig. 7. The ventilated facade system cladding falling off as a result of disturbing the adhesive application method.

The thermal insulation properties of the ventilated facade system are weakened by improper execution of the thermal insulation layer, e.g. by clogging the ventilation gaps between the thermal insulation and the claddings which prevents air circulation or leaking connection of individual thermal insulation units which lead to occurrence of thermal bridges (Figure 8).
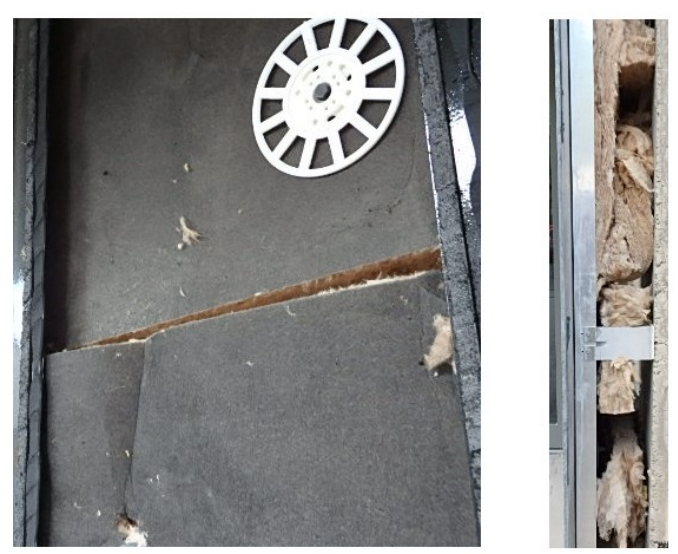

Fig. 8. Example of incorrect execution of thermal insulation.

A major factor behind durability, safe use and maintenance of technical and performance parameters of the ventilated facade systems assumed in the design is the constant building supervision carried out by appropriately qualified persons. The workmanship faults described above have been found at construction sites with insufficient number of supervisors. In many case in-process tests were not performed and temporary works were not inspected. For detailed description of inspection and acceptance activities carried out during assembly of the ventilated facade system see [2]. 


\section{Summary}

The paper presents the most common design and workmanship faults which affect the safe use, durability and performance parameters of the ventilate facade systems.

The ventilated facade system without the National or European Technical Acceptance cannot guarantee durable and safe use. The data included in these documents is of crucial importance when designing the facade system.

A major factor behind durability, safe use and maintenance of technical and performance parameters of the ventilated facade system is the quality of the design documentation. For basic components of the ventilated facade system design see [2].

Particular attention should be given to the technical conditions of the walls to which the ventilated facade system is to be attached. The walls shall meet the requirements of the design as well as NTA/ETA.

The quality of construction and assembly works has a crucial impact on the safe use of the ventilated facade systems, the guarantee of the assumed performance parameters for this type of products. The paper emphasizes the impact of the activities of the construction supervision authority on the quality of the ventilated facade system.

\section{References}

1. Document: EAD 090062-00-0404: Kits for external wall claddings mechanically fixed (, European Organisation for Technical Assessment, 2018)

2. O. Kopyłow, Warunki Techniczne Wykonania i Odbioru Robót Budowlanych. Część B: Roboty wykończeniowe, zeszyt 14: Elewacje wentylowane (Instytut Techniki Budowlanej, Warszawa, 2018) [in Polish]

3. K. Schabowicz, T. Gorzelańczyk, M. Szymków, Izolacje, 7, pp. 74-84 (2017)

4. Regulation of the Minister of Infrastructure of 12 April 2002 on technical conditions, which should correspond to the buildings and their location. Journal of Laws No. 75, item 690 as amended

5. J. Austin, Grenfell Tower refurbishers over insulated building to avoid repeat job. (Express Newspapers, 2017)

6. C. Marrs, Grenfell Tower: shocking tests results revealed. (Architects' Journal 2017)

7. H. Siddique, Grenfell Tower fire: police considering manslaughter charges (The Guardian 2017) 